\title{
A universal multifractal description applied to precipitation patterns of the Ebro River Basin, Spain
}

\author{
J. L. Valenciaa ${ }^{1, *}$, A. Saa Requejo ${ }^{2,3}$, J. M. Gascó ${ }^{3}$, A. M. Tarquis ${ }^{2,4}$ \\ ${ }^{1}$ Universidad Complutense, Escuela de Estadística, Dpto. de Estadística e Investigación Operativa III, Madrid, Spain \\ ${ }^{2}$ CEIGRAM, Universidad Politécnica de Madrid (UPM), Spain \\ ${ }^{3}$ Dpto. de Edafologia, ETSI Agrónomos, UPM, Spain \\ ${ }^{4}$ Dpto. de Matemática Aplicada en Ingeniería Agronómica, ETSI Agrónomos, UPM, Spain
}

\begin{abstract}
Water supplies in the Ebro River Basin are increasingly stressed, especially during the summer season. The year-to-year fluctuations in rainfall over this area exert vital influence on the regional hydrology, agriculture and several related industries in the region. Repeated anomalous rainfall in recent decades has had a devastating impact on this region, both socially and economically. We characterised the change in the rainfall variability pattern in the Ebro River Basin using universal multifractal (UM) analysis, which estimates the concentration of the data around the precipitation average $\left(C_{1}\right.$, codimension average), the degree of multiscaling behaviour in time ( $\alpha$ index) and the maximum probable singularity in the rainfall distribution $\left(\gamma_{\mathrm{s}}\right)$. Fourteen meteorological stations were selected based on the length of rainfall series and the climatic classification to obtain a representative untreated data set from the river basin. Daily rainfall series from 1957 to 2002 were obtained from each meteorological station and subdivided (1957-1980 and 1981-2002) to analyse the difference between the 2 periods. The general scenario observed in this study, through the UM parameters, can be summarised as follows: the range of variation of precipitation amounts was spatially more homogenous in 1980-2002 than in 1957-1979; at the same time, there is higher frequency of dry periods at different scales in 1980-2002; and in almost all of the stations, the range of precipitation over the years has been decreasing at a lower rate than the rainfall average. We then analysed the evolution of the UM parameters from 1957 to 2002. Continuous variations in $C_{1}$ and $\alpha$ were found for 2 of the stations, indicating that a precipitation regime change has begun in the last few decades and should be considered in the agricultural development of the region.
\end{abstract}

KEY WORDS: Multifractal $\cdot$ Climate change $\cdot$ Intermittence $\cdot$ Rainfall $\cdot$ Time series

\section{INTRODUCTION}

The Ebro River Basin $\left(\sim 85000 \mathrm{~km}^{2}\right.$, located in NE Spain) is characterised by the high spatial heterogeneity of its geology, topography, climatology and land use. Rainfall is one of the most important climatic variables studied owing to its non-homogenous behaviour in event and intensity, which creates drought, water runoff and soil erosion with negative environmental and social consequences (Walther et al. 2002). These episodes have traditionally been regarded as an agricultural problem; therefore, their economic impacts have been considered limited to rural environments.
However, current water uses cover a broader scope of economic activity and water deficits impact a larger number of sectors (Pérez Pérez \& Barreiro Hurlé 2009).

During the 20th century, many reservoirs and canals were constructed for agricultural irrigation, electricity production and domestic use (Comin 1999). Currently, irrigation is allowed in $7700 \mathrm{~km}^{2}$ of the region. Approximately 40 aquaculture systems that produce $35 \%$ of the total Spanish trout production (Batalla et al. 2004) are located in the region. The Ebro River is the most important river for Spanish water policy and facilitates several water transfer projects to other river basins as a consequence of desertification in some areas of Spain 
(Valencia 2007). A change in the rainfall pattern will limit the storage capacity for water that must be captured during winter to meet the heavy demands during the dry season (Batalla et al. 2004, Miller \& Yates 2005, Ludi 2009).

Gonzalez-Hidalgo et al. (2009) studied the monthly precipitation trends in the Mediterranean fringe of the Iberian Peninsula from 1951 to 2000. Their results demonstrated that no global behaviour could be observed in monthly trends except in March, which showed a generally negative trend. They suggested that precipitation studies based on a monthly scale might obscure the intrinsic variability that is required to understand the complex rainfall pattern in the region.

Royer et al. (2008) studied the change in universal multifractal (UM) parameters (Schertzer \& Lovejoy 1987) during different periods in the 21st century based on simulated rainfall data in a network of stations in France. The data in their studies were generated by several climatic models that were used by the IPCC. In their work, they noted that $C_{1}$ increased, and the increase of $C_{1}$ was greater than the decrease of $\alpha$.

The aim of the present study was to analyse the possible rainfall pattern trends in the Ebro River Basin using the daily precipitation series data available and following the trends of the UM parameters. Specifically, we analysed the mean and extreme rainfall trends in a resolution-independent characterization by means of the: (1) codimension average estimating the concentration of the mean of the rainfall in each station $\left(C_{1}\right)_{i}$ (2) deviation of the data from a monofractality case for the analysis of the higher frequency of the extreme precipitation values $(\alpha)$; and (3) maximum probable singularity for the analysis of the fluctuations in extreme values $\left(\gamma_{\mathrm{s}}\right)$. This will inform us about variation in precipitation extremes with more robust and stable parameters than empirical extremes.

With this purpose, 14 data series from meteorological stations located at different sites in the Ebro River Basin were analysed using daily rainfall data from 1957 to 2002. (1) The time series were divided in 2 periods, 1957-1979 and 1980-2002, to compare the UM parameters estimated for each period. (2) We estimated the UM parameters for each series over periods of $23 \mathrm{yr}$ with a lag time of 1 yr to study their evolution patterns.

\section{MULTIFRACTAL ANALYSIS}

The statistical multifractal nature of rain has been studied intensively (Tessier et al. 1996, Harris et al. 1997, Labat et al. 2002, García-Marin et al. 2008). One of the most important characteristics of multifractality is the self-similarity or invariance with the observation scale $(\lambda)$. A stochastic function $[x(t)]$ is self-affine if the following statement is true:

$$
x(t+\lambda \tau)-x(t) \approx \lambda^{H}[x(t+\tau)-x(t)]
$$

where the equality means that the probability function is identical $t$ is time and $\tau$ is the lag. The parameter $H$ estimates the dependency of the measured average on the scale used $(\lambda)$.

For the characterisation of each multifractal process, 2 main scale functions should be determined. One of these, $c(\gamma)$, characterises the singularity distribution depending on the scale used to measure $\lambda$.

$$
\operatorname{Pr}\left(x_{\lambda} \geq \lambda^{\gamma}\right) \approx \lambda^{-c(\gamma)}
$$

where $x_{\lambda}$ is the measure of the variable at the time scale $\lambda$.

The second function characterises the stochastic variable through its statistical moments. This function has introduced the concept of the scale moment function $[K(q)]$, which describes the multiscaling of the statistical moments of order $q$ as follows:

$$
\left\langle\left(x_{\lambda}\right)^{q}\right\rangle=\lambda^{K(q)}
$$

where the $x_{\lambda}$ parameter indicates the assembled statistical average. The relationship between the 2 scaling functions, $C(\gamma)$ and $K(q)$, can be expressed as follows:

$$
K(q)=\max _{\gamma}[q \gamma-c(\gamma)] \Leftrightarrow c(\gamma)=\max _{q}[q \gamma-K(q)]
$$

Scale-invariance properties are applied to $K(q)$ and $C(\gamma)$, showing the following parametric expressions:

$$
\begin{gathered}
\begin{cases}K(q)=\frac{C_{1}}{\alpha-1}\left(q^{\alpha}-q\right)+H q & \alpha \neq 1 \\
K(q)=C_{1} q \ln (q)+H q & \alpha=1\end{cases} \\
\begin{cases}c(\gamma-H)=C_{1}\left(\frac{\gamma}{C_{1} \alpha^{\prime}}+\frac{1}{\alpha}\right)^{\alpha^{\prime}} & \alpha \neq 1 \\
c(\gamma-H)=C_{1} \exp \left(\frac{\gamma}{C_{1}}-1\right) & \alpha=1\end{cases}
\end{gathered}
$$

where $\frac{1}{\alpha}+\frac{1}{\alpha^{\prime}}=1$

In other words, a multifractal function can be characterised with only 3 parameters:

(1) $H$ is the grade of non-conservative field. It measures the dependency on the scale of the measured event average. Higher values of $H$ indicate higher differences in the average depending on the time scale used.

(2) $C_{1}$ is the codimension average, which estimates the concentration of the average of the measure. A low $C_{1}$ value indicates a field that is close to the average almost everywhere. However, if $C_{1}$ is $>0.5$, the predominant characteristic of the measure is that it assumes values that are much lower than the average on 
most days and much higher than the average on others.

(3) The Levy $\alpha$ index indicates the deviation of the data from a monofractality case. The range of this parameter is $[0,2]$, where 2 corresponds to a log-normal distribution case. The $\alpha$ index represents the grade of variance of the measure, which in this case is the precipitation. A higher value of $\alpha$ indicates a higher frequency of the extreme precipitation values.

One of the advantages of universality is to reduce the statistical complexity of the processes of estimating these 2 parameters ( 3 parameters) when the data series is stationary (not stationary) (for more details see Schertzer \& Lovejoy 1991 and references therein).

One of the techniques of estimating these parameters is the double trace moment (DTM) developed by Lavalle et al. (1993). The DTM is considered one of the easiest techniques in terms of computation (Faleiro 1998) and consists of the following steps:

(1) Build the $\mu$-field with defined data as shown below:

$$
X_{\lambda}(\mu)=\frac{x_{\lambda}^{\mu}}{\left\langle x_{\lambda}^{\mu}\right\rangle}
$$

(2) Determine the moments of these values:

$$
\left\langle X_{\lambda}(\mu)^{q}\right\rangle=\frac{\left\langle x_{\lambda}^{q \mu}\right\rangle}{\left\langle x_{\lambda}^{\mu}\right\rangle^{q}} \approx \lambda^{K(q, \mu)}
$$

(3) Estimate $K(q, \mu)$ through double logarithmic regression that verifies the following relationship:

$$
K(q, \mu)=K(q, \mu)-q K(\mu)=\mu^{\alpha} K(q, 1)
$$

Therefore, $\alpha$ is estimated again through minimum squares in the $q$ and $\mu$ ranges that verify $\max (\mu, q, \mu)<$ $\min \left(q_{\mathrm{D}}, q_{\mathrm{s}}\right)$. This estimation should be made independently for $q$, after which the $\alpha$ dispersion can be used to evaluate the estimation error. The term $q_{\mathrm{s}}$ represents the maximum moment order that can be calculated with the required minimum precision for the given sample and $q_{\mathrm{D}}$ represents the maximum order that can be estimated after accounting for the statistical divergence.

In the next step, $C_{1}$ can be calculated based on $K(q, \mu)$ as follows:

or

$$
C_{1}=\frac{(\alpha-1) k(q, 1)}{q^{\alpha}-q}
$$

$$
C_{1}=\left(\frac{\partial K(q)}{\partial q}\right)_{q=1}
$$

The evolution of the extreme values is an important aspect in evaluating the effects of climatic change. To improve the extreme fluctuation analysis, the concept of maximum probable singularity $\left(\gamma_{\mathrm{s}}\right)$ is very useful. In the case of time series, it verifies tha $c\left(\gamma_{\mathrm{s}}\right)=1$ is independent from the scale $c\left(\gamma_{\mathrm{s}}\right)=d$, where $d$ is the dimension of the field in general. From Eq. (5) we can obtain the following equation analytically:

$$
\gamma_{s}=C_{1} \frac{\alpha}{\alpha-1}\left[\left(\frac{1}{C_{1}}\right)^{\frac{\alpha-1}{\alpha}}-\frac{1}{\alpha}\right]
$$

Here, $\gamma_{s}$ should be proportional to the logarithmic ratio between the maximum field value $\left[x_{\max }(\lambda)\right]$ and its average $(\langle x(\lambda)\rangle)$, as shown below:

$$
\frac{x_{\max }(\lambda)}{\langle x(\lambda)\rangle} \approx \lambda \gamma_{s}
$$

\section{STUDY SITE AND DATA DESCRIPTION}

The Ebro River Basin is one of the major Spanish depressions. It has a general bucket-shaped cross-section, where the mountain ranges define the following peripheral areas: the Pyrenees and Basque-Cantabrian Mountains in the north, the Iberian System in the south and the Catalan Mountains coastal chain in the east. These 3 mountain ranges leave between them a more depressed flat area termed the depression of the Ebro. This area is drained by the Ebro River, which runs in a northwest to southeast direction between the Pyrenees and the Iberian system. To the north of the main axis is a river basin area of $\sim 50000 \mathrm{~km}^{2}$, and to the south is an area of $\sim 30000 \mathrm{~km}^{2}$. The watershed region forms an isosceles triangle with its base in the east near the estuary and its vertex at the head of the Ebro River (Fig. 1).

The topographical conditions imply a continental Mediterranean climate in most of the Ebro basin. The extreme northwest, the western half of the Pyrenean border and the northern Iberian system are areas with oceanic climate. However, we must bear in mind that the transition between the oceanic and Mediterranean climates is progressive. The topographic disposition isolates the central sector from the influences of the sea, which are retained to a great extent by peripheral mountain ranges, thereby increasing the continental climate character in the rest of the watershed region and significantly decreasing precipitation. The aridity is one of the key defining features of the climate at the centre of the drainage basin.

With the exception of the Pyrenees and the northern sector of the Iberian mountain range, rainfall in the watershed region is scarce and is mainly concentrated in the spring and autumn seasons. Summer and winter generally register only the minimum rainfall. Precipitation, in addition to its scarcity, shows strong interannual and intermonthly irregularity, with long periods of no precipitation whatsoever (Martin-Vide et al. 2008).

The data presented in this study represent the complete daily rainfall series from 14 stations located in several regions of the river basin (Fig. 1). These stations were selected considering the length of the daily precipitation series and the absence of missing data and multiannual gaps (i.e. there were no gaps in the data). 


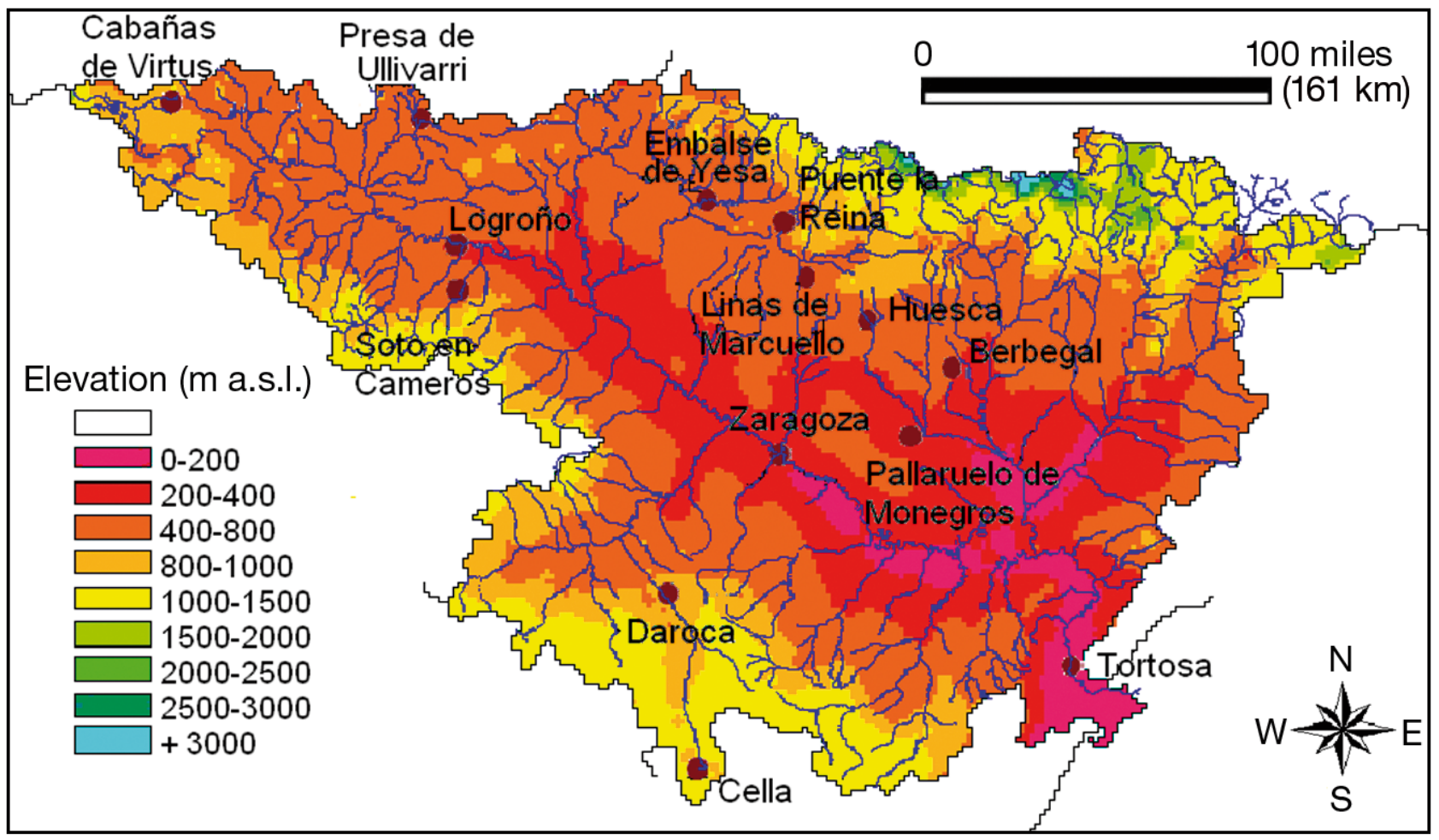

Fig. 1. Distribution of the 14 stations analysed along the Ebro River Basin

Therefore, data analysis was possible without any reconstruction. One of the 14 stations was close to the origin of the river (Cabañás de Virtus) and exhibited an almost oceanic climate, whereas another that was close to the end of the river (Tortosa) clearly exhibited a Mediterranean climate. Some stations, such as Cella and Daroca, showed continental climates, whereas others, such as Zaragoza and Pallaruelo de Monegros, were located in an arid area. In addition, the following stations were close to the Pyrenees and followed a humid regime: Linas de Marcuello, Puente la Reina, Presa de Ullivarri Gamboa and Embalse de Yesa. These selected stations are a complete representation of the different climatic types found in the river basin.

The time series data were provided by the Cuenca Hidrográfica del Ebro. Data were available for a period of $46 \mathrm{yr}$ for each station from January 1957 to December 2002. The daily rainfall averages of all stations for each year are shown in Fig. 2, and Table 1 presents the statistical moments and maximum recordings for each 5-yr period. In Fig. 2 and Table 1, an important change can be perceived after 1981, i.e. the period between 1982 and 1986 shows a rainfall decrease that is greater than $10 \%$ and this decrease is concentrated mainly in the mountainous area.

The kurtosis values for all years (Table 1) were positive, indicating longer tails than in Gaussian distributions. The skewness values (Table 1) pointed out that the right tail was longer than the left. Although skewness was similar across all years studied, the kurtosis values varied and presented maximum values from 1962-1966 and 1982-1986. For the rest of the manuscript, we will use the station codes shown in Table 2 instead of the station names to facilitate the discussion.

\section{RESULTS AND DISCUSSION}

\subsection{Comparison between 1957-1979 and 1980-2002}

The DTM technique was applied separately to the daily rainfall series at each of the 14 rainfall gauges over the 2 different periods (1957-1979 and 1980-2002).

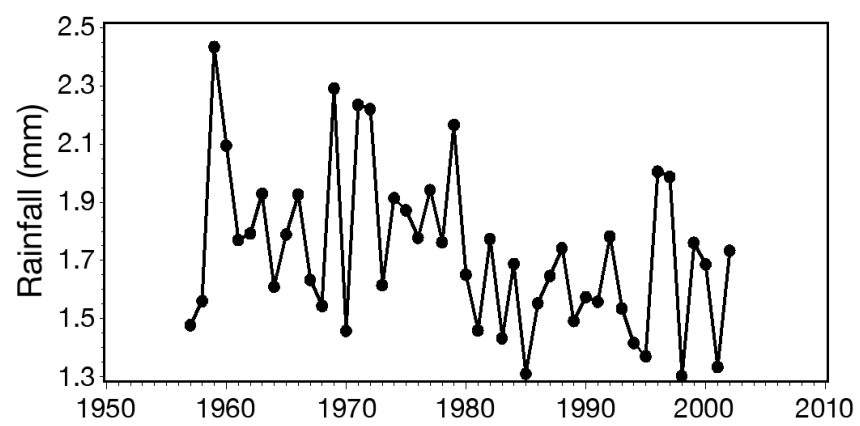

Fig. 2. Mean daily rainfall for each year for all 14 stations combined 
Table 1. Mean ( $\pm \mathrm{SD})$, maximum precipitation, kurtosis, skewness and coefficient of variation (CV) of daily rainfall values obtained at the 14 meteorological stations in $5 \mathrm{yr}$ periods

\begin{tabular}{|lccccc|}
\hline Period & Mean & $\begin{array}{c}\text { Maximum } \\
\text { precipitation } \\
(\mathrm{mm})\end{array}$ & Kurtosis & Skewness & CV \\
& & & & & \\
\hline $1957-1961$ & $1.85 \pm 5.82$ & 116.60 & 60.39 & 6.21 & 314.04 \\
$1962-1966$ & $1.81 \pm 5.58$ & 176.50 & 81.34 & 6.56 & 308.23 \\
$1967-1971$ & $1.83 \pm 5.49$ & 124.50 & 54.38 & 5.86 & 299.65 \\
$1972-1976$ & $1.88 \pm 5.74$ & 99.40 & 49.04 & 5.84 & 305.50 \\
$1977-1981$ & $1.79 \pm 5.22$ & 82.50 & 39.40 & 5.30 & 290.77 \\
$1982-1986$ & $1.55 \pm 4.67$ & 119.70 & 70.03 & 6.29 & 301.21 \\
$1987-1991$ & $1.60 \pm 4.82$ & 88.19 & 44.49 & 5.55 & 300.89 \\
$1992-1996$ & $1.62 \pm 5.11$ & 110.30 & 58.12 & 6.24 & 315.01 \\
$1997-2001$ & $1.61 \pm 5.08$ & 118.90 & 57.43 & 6.10 & 315.09 \\
\hline
\end{tabular}

riod to the second between stations. This was clearly reflected by the reduction in the variance coefficient. The $H$ parameter changed from positive to negative from one period to the next. Based on these results, we arrived at the following conclusions:

- The stations with lower values of the $\alpha$ index, namely, A7, B5 and A8, showed the greatest increase in this index, whereas stations with higher $\alpha$ values, namely, A2 and B2, showed reductions in this index the second period. Therefore, from the first period to the second, the trend has been to homogenise the $\alpha$ values among the 14 stations. The differences between the highest and lowest were reduced.

The estimated values of the $K(q, \mu)$ parameter for $q=$ 1.1 and for some $\mu$ values at Tortosa were smaller than 1 in the first period (Fig. 3). This result illustrates that in the first step of the DTM application, only the largest values of $\lambda$ are used to estimate the slopes. Using Eq. (8), it is possible to estimate $\alpha$ based on the slope of a $\log$-log regression line (Fig. 4).

The universal parameters estimated were similar to those obtained from previous analyses of local rainfall measured at the observation stations (Labat et al. 2002, Tessier et al. 1996, García-Marin et al. 2008). The changes produced in both non-overlapping periods are shown in Table 2. Comparison of these changes showed that the variations in $C_{1}$ and $K(q=2)$ were the same, whereas the $\alpha$ values decreased from the first pe-
- The $C_{1}$ behaviour, however, was different. In general, the increase in $\mathrm{C}_{1}$ was lower than the increase in $\alpha$. However, this increase was observed in stations where the initial value in the first period was high. There was a slight increase in the frequency of the drought season in the second period, mainly for the stations that showed a higher frequency of drought during the first period.

- Because $K(q)$ is an increasing function with respect to $\alpha$ and $C_{1}$, a slight increase in $K(q=2)$ was also observed in some pluviometric stations. However, only a moderate decrease was found for Stn A3.

- A moderate increase in the maximal probable singularity parameter $\gamma_{\mathrm{s}}$ was observed for all of the stations except A3 and B4. This parameter is related to the

Table 2. Universal multifractal parameters for both periods of study (1957-1979 and 1980-2002) for each rainfall gauge: codimension average $\left(C_{1}\right)$, multifractality index $(\alpha)$, singularity in the rainfall distribution $\left(\gamma_{\mathrm{s}}\right)$, grade of non-conservative field $(H)$ and the Hurst exponent $[K(q=2)]$

\begin{tabular}{|c|c|c|c|c|c|c|c|c|c|c|c|}
\hline \multirow[b]{2}{*}{ Station } & \multirow[b]{2}{*}{ Rain gauge } & \multicolumn{5}{|c|}{-1957-1979 } & \multicolumn{5}{|c|}{$-1980-2002$} \\
\hline & & $C_{1}$ & $\alpha$ & $\gamma_{\mathrm{s}}$ & $H$ & $K(q=2)$ & $C_{1}$ & $\alpha$ & $\gamma_{\mathrm{s}}$ & $H$ & $K(q=2)$ \\
\hline A1 & Cabañas de Virtus & 0.32 & 0.58 & 0.56 & 0.129 & 0.38 & 0.30 & 0.68 & 0.58 & 0.088 & 0.37 \\
\hline A2 & Presa de Ullivarri-Gamboa & 0.28 & 0.68 & 0.55 & 0.073 & 0.35 & 0.32 & 0.61 & 0.58 & -0.080 & 0.39 \\
\hline A3 & Embalse de Yesa & 0.28 & 0.79 & 0.58 & 0.037 & 0.35 & 0.24 & 0.79 & 0.53 & 0.022 & 0.31 \\
\hline A4 & Puente la Reina & 0.32 & 0.63 & 0.58 & 0.051 & 0.39 & 0.32 & 0.63 & 0.59 & 0.045 & 0.40 \\
\hline A5 & Linas de Marcuello & 0.33 & 0.51 & 0.55 & 0.026 & 0.39 & 0.34 & 0.54 & 0.58 & 0.028 & 0.40 \\
\hline A6 & Huesca & 0.40 & 0.56 & 0.66 & -0.025 & 0.47 & 0.41 & 0.58 & 0.68 & -0.050 & 0.49 \\
\hline A7 & Berbegal & 0.46 & 0.38 & 0.67 & -0.092 & 0.52 & 0.46 & 0.44 & 0.69 & -0.009 & 0.53 \\
\hline A8 & Pallaruelo de Monegros & 0.47 & 0.44 & 0.70 & -0.081 & 0.54 & 0.47 & 0.50 & 0.72 & -0.070 & 0.55 \\
\hline B1 & Logroño & 0.38 & 0.55 & 0.64 & -0.052 & 0.46 & 0.40 & 0.60 & 0.68 & -0.058 & 0.48 \\
\hline B2 & Soto en Cameros & 0.35 & 0.62 & 0.62 & -0.033 & 0.42 & 0.39 & 0.54 & 0.64 & -0.088 & 0.46 \\
\hline B3 & Zaragoza & 0.45 & 0.52 & 0.70 & 0.008 & 0.53 & 0.47 & 0.54 & 0.73 & -0.100 & 0.55 \\
\hline B4 & Daroca & 0.39 & 0.57 & 0.66 & -0.067 & 0.47 & 0.39 & 0.52 & 0.64 & -0.075 & 0.47 \\
\hline B5 & Cella & 0.47 & 0.40 & 0.68 & -0.082 & 0.53 & 0.46 & 0.48 & 0.70 & -0.054 & 0.53 \\
\hline B6 & Tortosa & 0.49 & 0.46 & 0.73 & 0.030 & 0.57 & 0.51 & 0.49 & 0.76 & 0.061 & 0.59 \\
\hline \multicolumn{2}{|c|}{ Mean } & 0.38 & 0.55 & 0.63 & 0.006 & 0.46 & 0.39 & 0.57 & 0.65 & -0.024 & 0.47 \\
\hline \multicolumn{2}{|c|}{$\mathrm{SD}$} & 0.07 & 0.11 & 0.06 & 0.067 & 0.07 & 0.08 & 0.09 & 0.07 & 0.062 & 0.08 \\
\hline \multicolumn{2}{|c|}{ Kurtosis } & -1.48 & 0.33 & -1.39 & -0.597 & -1.48 & -0.73 & 1.52 & -1.09 & -1.201 & -0.759 \\
\hline \multirow{2}{*}{\multicolumn{2}{|c|}{$\begin{array}{l}\text { Skewness } \\
\text { CV }(\%)\end{array}$}} & 0.00 & 0.44 & -0.12 & 0.42 & -0.01 & -0.33 & 1.09 & -0.15 & 0.542 & -0.33 \\
\hline & & 19.11 & 20.28 & 9.61 & -1196 & 16.55 & 20.09 & 16.08 & 10.64 & -255.4 & 17.52 \\
\hline
\end{tabular}




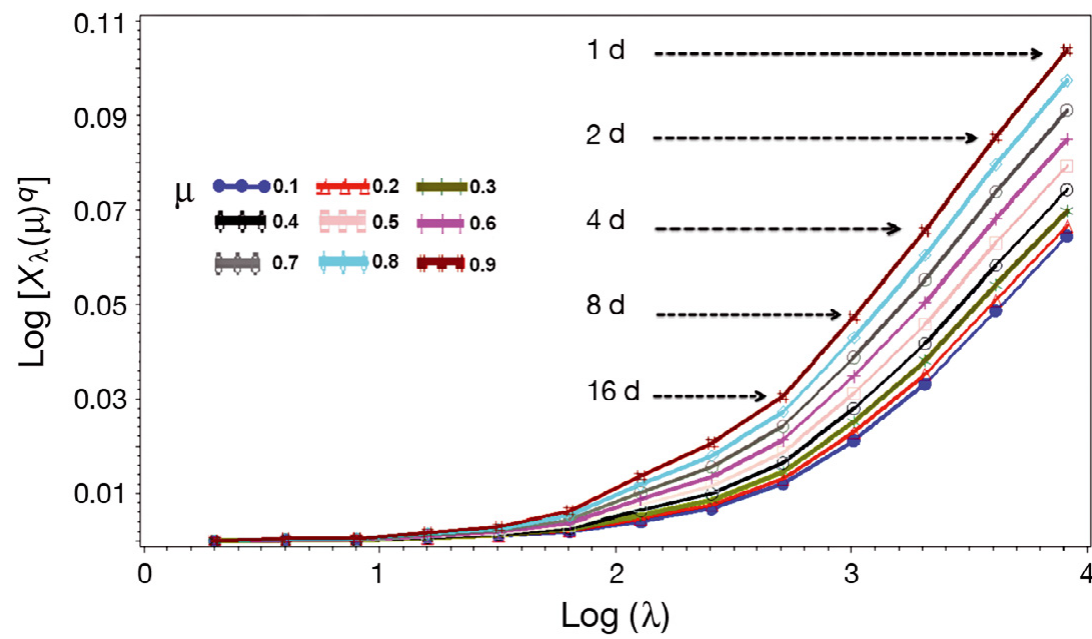

Fig. 3. Illustration of the double trace moment (DTM) first step at Tortosa for $q=1.1$. The slope for the highest scale values $(\lambda)$ determines the slope of the $\log -\log$ of the DTM versus its time resolution

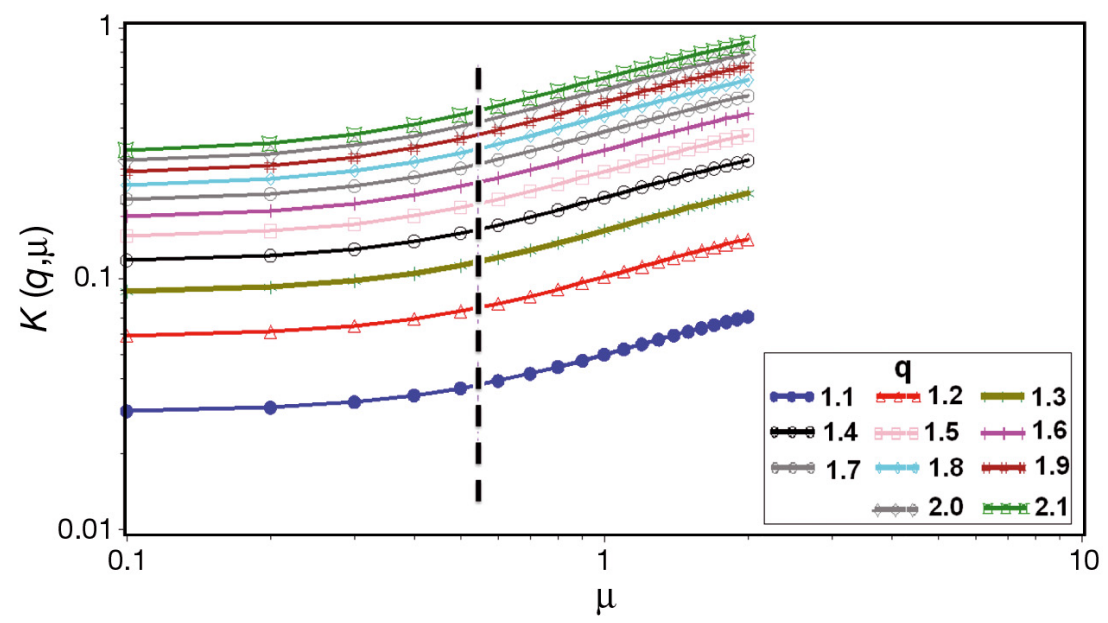

Fig. 4. Illustration of the multifractality index $(\alpha)$ calculation as the average of the slopes estimated from $\log \times \log$ plots of the scale moment function $[K(q, \mu)]$ versus time scale $(\mu)$

ratio between the precipitation range and average at any time scale, which implies that, if there is a greater decrease in the average, there is a higher probability of relative precipitation extreme values occurring.

The UM parameters for each period and each station are shown in Fig. 5. We sorted the stations based on their proximity to the sea, where the Ebro River terminates. The right side of the figure represents greater proximity to the sea. The increase in $C_{1}$ as the stations approach the sea (Fig. 5A) was evident in both periods, with more frequent gaps in the rainfall events, and values ranged from 0.24 to 0.51. Except for Stns A2, A3 and $\mathrm{B} 2$, none of the stations presented significant differences in $C_{1}$ between the 2 periods.

At the same time, $\alpha$ (Fig. 5B) decreased from Stn A1 to Stn B6 owing to the increasingly narrow precipita- tion range, and there are more days without rain. However, the range of the multifractality index for all stations was $<1$.

The maximum probable singularity, $\gamma_{\mathrm{s}}$ (Fig. 5C), showed an increasing trend from Stn A1 to Stn B6. Excluding Stns A3, A5 and B4, this trend was quite smooth. Therefore, we concluded that the proximity to the coast increases the probability of occurrence of the relative extreme precipitation values.

These general UM parameter patterns observed in the Ebro River Basin are in accordance with previous work describing the variability among seasons and years owing to the North Atlantic Oscillation (NAO), Mediterranean Oscillation (MO) and Western MO (WEMO) (Gonzalez-Hidalgo et al. 2009, López \& Frances 2010).

\subsection{Evolution of UM parameters from 1957 to 2002}

The results presented above illustrate the differences in the UM parameters for each station between the period 1957-1979 and the more recent period 1980-2002. Now, we will study the evolution of these parameters across these periods to determine whether the changes were smooth, presented any stationary components or had any particular cycles.

With this target in mind, the UM parameters were estimated in a systematic manner by gliding a window of length $8192\left(2^{13}\right)$ along the daily precipitation series. The first window began on 1 January 1957 and the last window ended on 31 December 2002. The lag time between the first points of 2 consecutive windows was $1 \mathrm{yr}$ (365 d). The results of these analyses for each meteorological station along are shown in Figs. 6, 7 and 8 and visualise the evolution of $\mathrm{C}_{1}, \alpha$ and $\gamma_{\mathrm{s}}$, respectively.

The evolution of $C_{1}$ was steady at almost all of the stations (Fig. 6B) and the values ranged from 0.30 to 0.50 . However, there were a few exceptions. At Stn A3, $C_{1}$ presented the lowest values and maintained a linear decrease until 1989, after which it showed a slight increase (Fig. 6A). At Stns A2 and B2 (Fig. 6C), $C_{1}$ showed a continuous increase. 

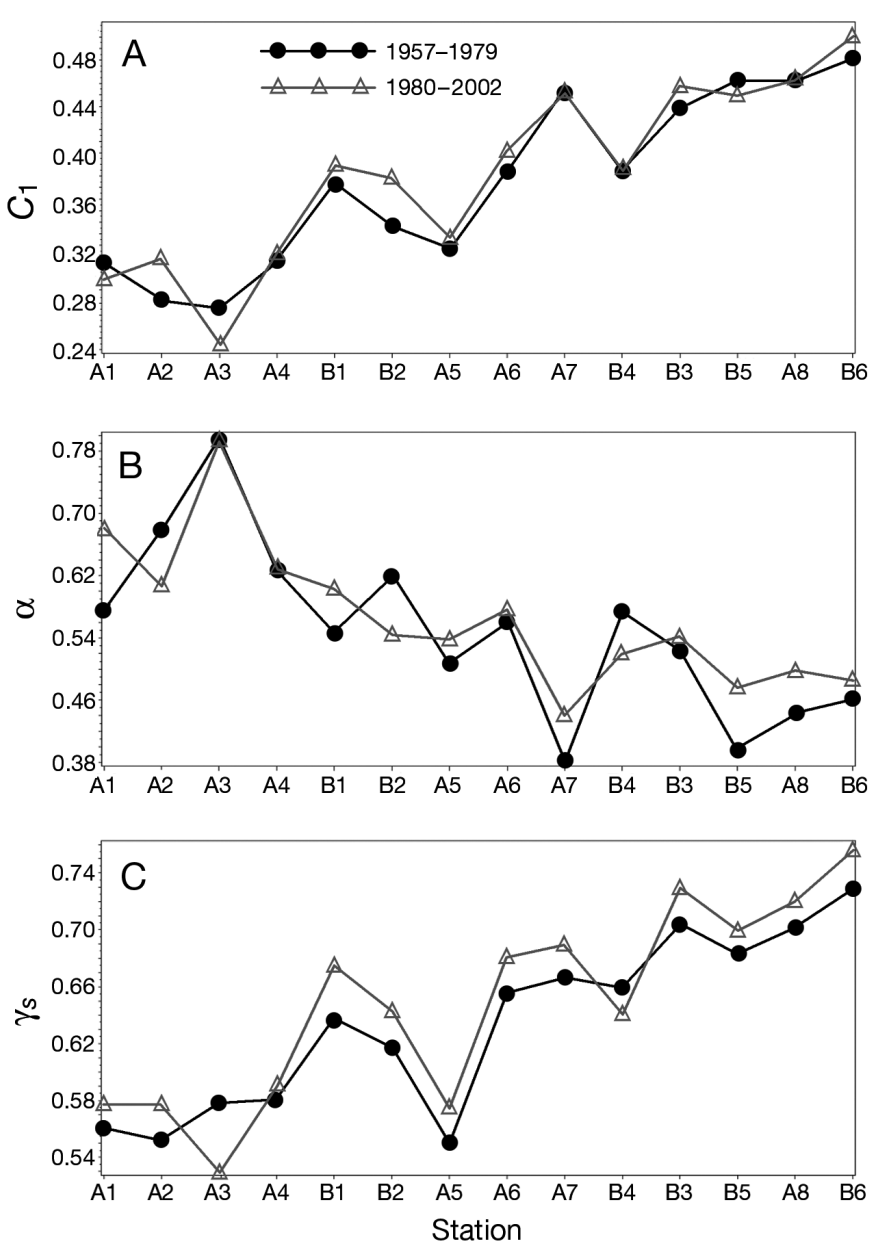

Fig. 5. Variation of (A) the codimension average $\left(C_{1}\right)$, (B) the multifractality index $(\alpha)$ and $(C)$ singularity in the rainfall distribution $\left(\gamma_{\mathrm{s}}\right)$, depending on the station and the time interval over which they are estimated. Stations are in order of increasing distance to the Ebro River mouth

Again, 3 different patterns were observed for the $\alpha$ index. The most frequent pattern was a steady series with values ranging from 0.40 to 0.83 (Fig. 7B). Stns A2 and B2 showed a decreasing trend in $\alpha$, which became clearer after 1990. Four stations (Fig. 7C) presented an increase in $\alpha$; however, the slopes of these increasing trends were different for each of these stations.

The evolution of $\gamma_{\mathrm{s}}$ was very similar to the evolution of $C_{1}$. Stn A3 showed the same pattern (Fig. 8A). Three stations, namely, A2, A1 and B1, presented an increase in $\gamma_{\mathrm{s}}$ (Fig. 8C); however, the behaviour of $\gamma_{\mathrm{s}}$ at A1 and B1 was different from that of $C_{1}$ (Fig. 6C). The rest of the stations presented values that were more constant, although their steady character was less pronounced (Fig. 8B).

Of all of these observations, only 2 stations, A2 and B2, were prone to showing changes in precipitation patterns. Both presented an increase in $C_{1}$ and a decrease in $\alpha$, creating a scenario that was similar to the simulations performed by Royer et al. (2008). These tendencies were clearer from 1990 onwards. Another interesting case was Stn A3, which presented an evident change in $\gamma_{\mathrm{s}}$ and $C_{1}$ trends in 1989. The rest of the stations did not present clear trends in the UM parameters.

\section{CONCLUSIONS}

Climate signals generally vary over a wide range of scales. In the present study, we analysed the evolution of multiscale rainfall variability in the Ebro River Basin through 14 time series at different locations and under different climatic conditions. The increase of extreme precipitation values such as maximum daily rainfall was due to intermittency as well as multifractality.

The variation of the $\alpha$ index from the first period to the second tended to homogenise spatially; lower values increased and higher values decreased. Therefore, the range of variation of precipitation amounts was spatially more homogenous in 1980-2002.

An increase in $C_{1}$ was observed in the second period analysed, especially for the stations with the highest values during the first period. The increase in $C_{1}$ values of rainfall occurrences suggests a higher frequency of dry periods at time scales. However, a longer rainfall series is needed to confirm this tendency.

For the stations studied, based on the $\gamma_{\mathrm{s}}$ values for both periods, we concluded that the range in the amount of rainfall has decreased with time at a lower rate than the precipitation average for almost all of the stations. The spatial pattern found in the UM parameter values sorted by distance to the mouth of the Ebro River was clear and in agreement with previous work (Tessier et al. 1996, Royer et al. 2008) showing an increase with the proximity to the coast.

Only 2 stations, Presa de Ullibarri-Gamboa (A2) and Soto en Cameros (B2), showed continuous variations over time in $C_{1}$ and $\alpha$ values that could point out the beginning of a precipitation regime change during the last decade.

These variations observed in UM parameters must be taken into consideration for the rural development in the region, for example in irrigation schemes, soil erosion and flood control. In summary, this study confirms some postulates drawn by conservative scientists who refuse a catastrophic intepretation, but take the middle ground regarding climate change, and suggest that there is a weak trend towards a new climatic situation, including the precipitation regime. 

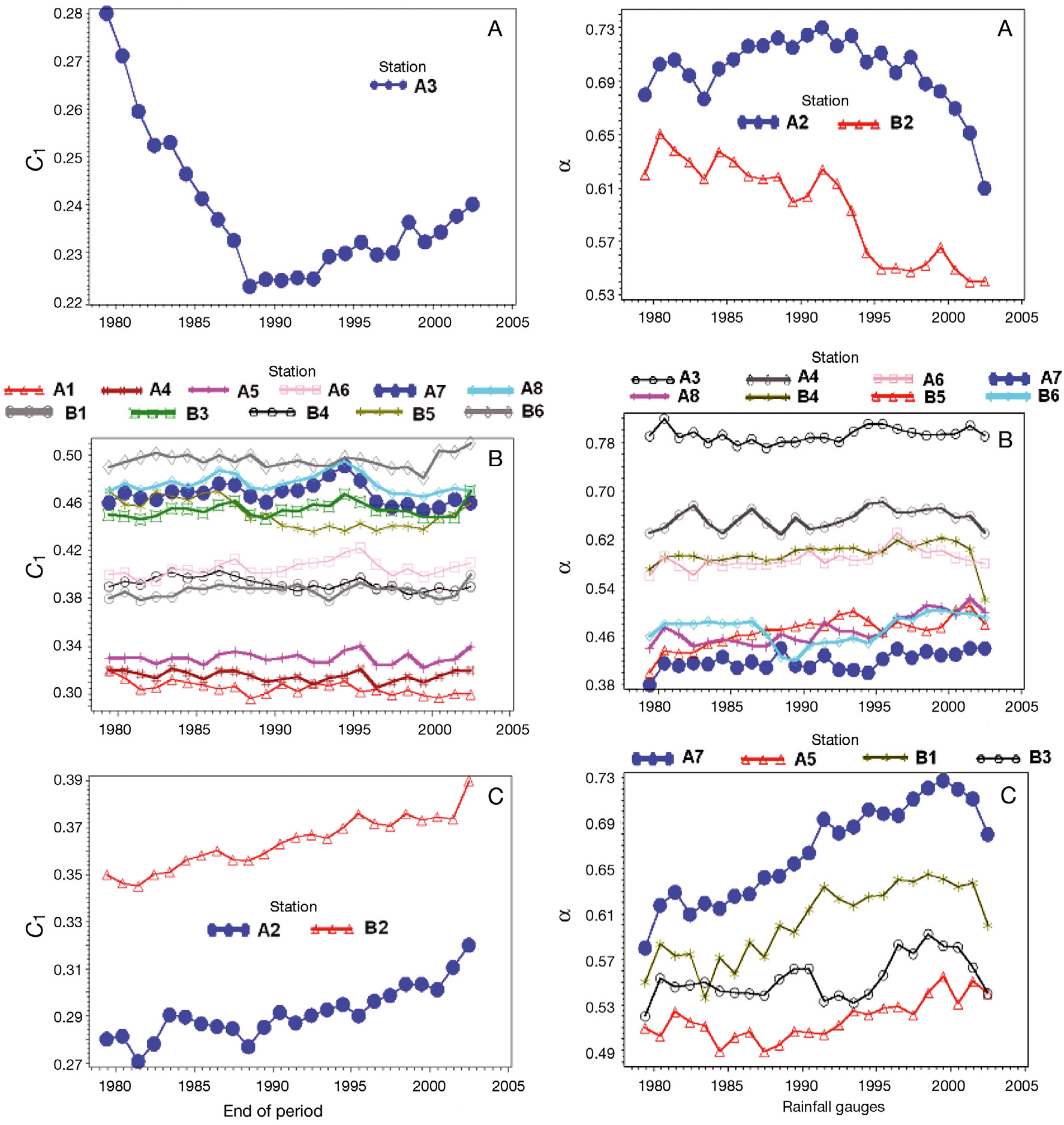

Fig. 6. Evolution of the codimension average $\left(C_{1}\right)$ for the 14 stations studied in the Ebro River Basin for the month of January. $(A, B, C)$ Certain stations depicted in separate graphs for descriptive purposes

Fig. 7. Evolution of the multifractality index $(\alpha)$ for the 14 stations studied in the Ebro River Basin in the month of January. $(A, B, C)$ Certain stations depicted in separate graphs for descriptive purposes 

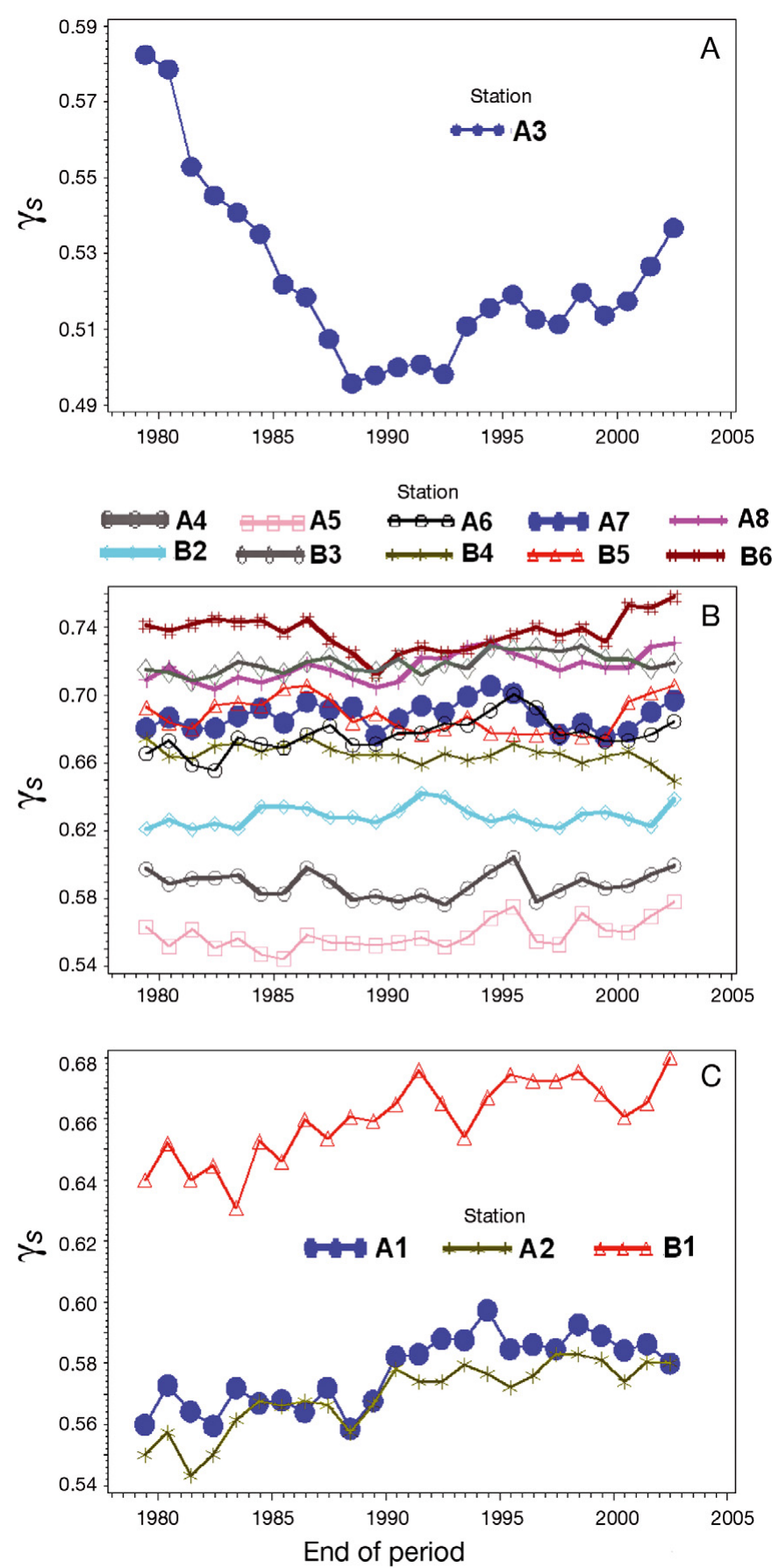

Fig. 8. Evolution of singularity in the rainfall distribution $\left(\gamma_{\mathrm{s}}\right)$ for the 14 stations studied in the Ebro River Basin in the month of January. $(\mathrm{A}, \mathrm{B}, \mathrm{C})$ Certain stations depicted in separate graphs for descriptive purposes

Acknowledgements. We greatly acknowledge the anonymous referees for their suggestions and constructive criticism. Financial support to this research by the Agencia Catalana del Agua Generalitat de Catalunya (contract Cod. P060225571), and by Entidad Estatal de Seguros Agrarios (ENESA - MAPA) (contract Cod. P030225764) is gratefully acknowledged

\section{LITERATURE CITED}

Batalla RJ, Gómez CM, Mathias Kondolf G (2004) Reservoirinduced hydrological changes in the Ebro River Basin (NE Spain). J Hydrol 290:117-136

Comin FA (1999) Management of the Ebro River Basin: past, present and future. Water Sci Technol 40:161-168

Faleiro E (1998) Estructura multifractal y aplicaciones de las fluctuaciones en cascadas atmosféricas producidas por rayos cósmicos. PhD thesis, Universidad Complutense de Madrid (in Spanish)

García-Marin FJ, Jimenez-Hornero FJ, Ayuso JL (2008) Multifractal analysis as a tool validating a rainfall model. Hydrol Process 22:2672-2688

Gonzalez-Hidalgo JC, Lopez-Bustins JA, Stepánek P, MartinVide J, de Luis M (2009) Monthly precipitation trends on the Mediterranean fringe of the Iberian Peninsula during the second half of the twentieth century (1951-2000). Int J Climatol 29:1415-1429

$>$ Harris D, Seed A, Menabde M, And Austin G (1997) Factors affecting multiscaling analysis of rainfall time series. Nonlinear Process Geophys 4:137-155

> Labat D, Mangin A, Ababou R (2002) Rainfall-runoff relations for karstic springs: multifractal analyses. J Hydrol 256:176-195

Lavalle D, Lovejoy S, Schertzer D, Ladoy P (1993) Nonlinear variability and landscape topography analysis and simulation In: De Cola L, Lam N (ed) Fractals in geography. Prentice Hall, Englewood Cliffs, NJ, p 158-192

López J, Frances F (2010) Influence of the North Atlantic Oscillation and the Western Mediterranean Oscillation in the maximum flow events in Spain. Proc Int Workshop Advances in Statistical Hydrology, May 23-25, Taormina

Ludi E (2009) Climate change, water and food security. Overseas Development Institute Background Note, ODI, London

> Martin-Vide J, Sanchez-Lorenzo A, Lopez-Bustins JA, Cordobilla MJ, García-Manuel A, Raso JM (2008) Torrential rainfall in northeast of the Iberian Peninsula: synoptic patterns and WeMO influences. Adv Sci Res 2:99-105

Miller K, Yates D (2005) Climate change and water resources: a primer for municipal water providers. AWWA Research Foundation, Denver, CO

Pérez Pérez L, Barreiro Hurlé J (2009) Assessing the socioeconomic impacts of drought in the Ebro river basin. Span J Agric Res 2:269-280

- Royer JF, Biaou A, Chauvin F, Schertzer D, Lovejoi S (2008) Multifractal analysis of evolution of simulated precipitation over France in a climate scenario. Geoscience 340:431-440

Schertzer D, Lovejoy S (1987) Physical modeling and analysis of rain and clouds by anysotropic scaling of multiplicative processes. J Geophys Res D 8:9693-9714

Schertzer D, Lovejoy S (1991) Nonlinear geodynamical variability: multiple singularities, universality and observables. In: Schertzer D, Lovejoy S (eds) Non-linear variability in geophysics. Kluwer, Dordrecht, p 41-82

$>$ Tessier Y, Lovejoy S, Hubert P, Schertzer D, Pecknold S (1996) Multifractal analysis and modelling of rainfall and river flows and scaling, causal transfer functions multifractals: theory and observations for rain and clouds. J Geophys Res 101:26427-26440

Valencia JL (2007). Estudio estadístico de la calidad de las aguas de la cuenca hidrográfica del río Ebro. PhD thesis, Universidad Politécnica de Madrid (in Spanish)

Walther GR, Post E, Convey P, Menzel A and others (2002) Ecological responses to recent climate change. Nature 416:389-395

Proofs received from author(s): October 22, 2010 